\title{
Comparison of Magnetic Resonance Urography (MRU) with Intravenous Pyelography (IVP) in Evaluation of Patients with Hydronephrosis on Ultrasonography Due to Pelvi-Ureteric Junction Obstruction
}

\author{
Gulzar Ahmad Bhat' ${ }^{1}$ Tarooq Ahmad Reshi' ${ }^{2}$, Asiya Rashid1 \\ ${ }^{1}$ Department of General Surgery, SKIMS, Srinagar, India \\ ${ }^{2}$ Department of Surgery, SKIMS, Srinagar, India \\ Email:drbhatgulzar@gmail.com,drtariqreshi@gmail.com, asiya7rashid@gmail.com
}

Received 20 November 2015; accepted 28 May 2016; published 31 May 2016

Copyright (C) 2016 by authors and Scientific Research Publishing Inc.

This work is licensed under the Creative Commons Attribution International License (CC BY).

http://creativecommons.org/licenses/by/4.0/

(c) (i) Open Access

\begin{abstract}
The objective of this study was to compare Magnetic Resonance Urography (MRU) with Intravenous Pyelography (IVP) in evaluation of patients with hydronephrosis on ultrasonography. 49 patients of hydronephrosis on USG were enrolled for the study from Jan. 2011 to Dec. 2012. All patients under went Intravenous Urography (IVU). MRU was done to determine the anatomical details and function of each renal unit. MRU was performed on a 1.5 tesla unit (Magneton Avento; Siemens, Erlangen, Germany). Static T2-weighted Magnetic Resonance Urography (MRU) was performed by using a standard fast spin echo technique. Dynamic study was performed after injecting intravenous diuretic followed by Gadolinium contrast media. Morphological results of MRU were compared with IVU. The anatomical findings were compared with operative findings. Stastical analysis was performed and data expressed as mean \pm SD. MRU showed PUJ obstruction in 41 out of 45 patients $(\mathbf{9 1 . 1 \% )}$ ). We concluded that MRU can provide complete diagnostic evaluation of entire urinary tract in a single session and has potential to replace IVP.
\end{abstract}

\section{Keywords}

USG (Ultrasonography), MRU (Magnetic Resonance Imaging), IVU (Intravenous Urography) 


\section{Introduction}

Obstructive uropathy is the structural or functional abnormality in urinary tract that impedes the normal flow of urine. Disorders like calculi, tumors, strictures and anatomical abnormalities and can result in pain, urinary tract infection, loss in renal function, or possibly sepsis and death [1]. Progressive back pressure on the kidneys and ureters can occur and cause hydroureter and hydronephrosis. Hydronephrosis causes permanent nephron damage and renal failure [2]. Symptoms and signs vary with the degree and rapidity of onset of obstructive uropathy as well with the site of obstruction. Most of the patients are asymptomatic. Upper ureteral or renal pelvic lesions cause flank pain, whereas lower ureteral obstruction causes pain that may radiate to testicles or labia. The distribution of renal and ureteral pain is usually along T11 and T12 dermatomes. Pelviureteric junction obstruction (PUJO) is a condition in which urine is unable to travel from the renal pelvis to the bladder because of a blockage occurring at the UPJ. The etiology of PUJ obstruction includes both congenital and acquired conditions with majority of cases being congenital. Stone disease, postoperative or inflammatory strictures, and urothelial neoplasms are some of acquired causes. A congenital PUJ obstruction may be due to either an intrinsic or an extrinsic cause, or in some cases, both [3]. Most common intrinsic obstructions are the result of an adynamic segment. [4] or an alteration of the collagen fibers and composition between and around the muscular cells [5]. The standard repair for UPJ obstruction has historically been open pyeloplasty. The strategy for management of renal obstruction is based upon precise delineation of the anatomy of both Reno-ureteral units, as well as accurate estimation of the split renal function.

Magnetic Resonance Urography (MRU): static fluid imaging wherein static or slow-flowing fluids in the body are imaged as high signal intensity, high contrast, bright structures against a dark background with very low signal intensity, referred to by some researchers as "hydrographic contrast” [6]. The most important advantages of MRI are the free choice of slice orientation, high soft tissue contrast and high resolution as well as the lack of radiation. MRU performed with contrast material can meet all demands of clinical urography and, in some cases, could replace conventional X-ray Urography [7]-[9]. The first MR image was published in 1973 [10]. By combining unenhanced sequences with multiphase contrast enhanced and excretory phase imaging, a comprehensive assessment of the kidneys, ureters, bladder and surrounding structures is possible. Allergies to gadolinium based contrast agents are exceedingly rare occurring at a rate of $0.03 \%-0.1 \%$ [11]-[14]. There have been reports of serious adverse reaction called Nephrogenic Systemic Fibrosis (NFS) that can occur after exposure to extracellular, non-ionic low osmolar gadolinium based contrast agents [15] [16].

\section{Material and Methods}

This study was conducted in the departments of Urology and Radiodiagnosis \& Imaging, Sher-I-Kashmir Institute of Medical Sciences Srinagar. This study was duely approved by the ethical committee of our institution. This prospective study included 49 patients of hydronephrosis on USG over a period of two years between January 2011 to December 2012. Patients were evaluated by history, clinical examination and USG abdomen. All patients under went intravenous Urography (IVU) and a DTPA Scan for determining split renal function and GFR calculation of each kidney. All patients underwent gadolinium-enhanced magnetic resonance imaging (Gd-MRI) to determine the anatomy and function of renal units by calculating the GFR of each unit.

Patients with hydronephrosis on USG with normal kidney function were included in the study. Patients with Ferro-magnetic implants, Patients who had claustrophobia, Patients with Vagus nerve stimulators, Implanted Cardioverters-Defibrillators (ICD), cochlear implants, deep brain stimulators etc were excluded from study. All the information was recorded in a pre-structured proforma and analyzed by appropriate statistical analysis.

Stastical analysis was performed and data expressed as mean \pm SD.

\section{Results}

The total number of patients included in the study was 49, out of which 31 (63.2\%) were males and 18 (36.7\%) females with mean age 37.3 years. 21 (42.8\%) out of 49 patients were asymptomatic (Table 1). flank pain was second most common presentation and was present in 16 (32.6\%) of patients (Figure 1).

On USG hydronephrosis was present in all (49\%, 100\%) patients. PUJ Obstruction was detected only in 33 (67.5\%) patients as a cause for hydronephrosis on Ultrasonography (USG). All patients were subjected to Intra-venous Pyelography (Image 1). Contrast uptake was normal in 44 patients and decreased in 5. PUJ obstruction was detected in 39 (79.5\%) patients (Table 2 \& Figure 2). 
Table 1. Presentation of patients.

\begin{tabular}{llll}
\hline Presenting Symptoms & & & \\
& & N & $\%$ \\
& & 3 & 6.1 \\
Pain Flank & Right & 9 & 18.3 \\
& Left & 4 & 8.1 \\
Dysuria & Bilateral & 7 & 14.2 \\
Hematuria & & 2 & 4 \\
Increased Frequency & & 3 & 6.1 \\
Asymptomatic & & 21 & 42.8 \\
\hline
\end{tabular}

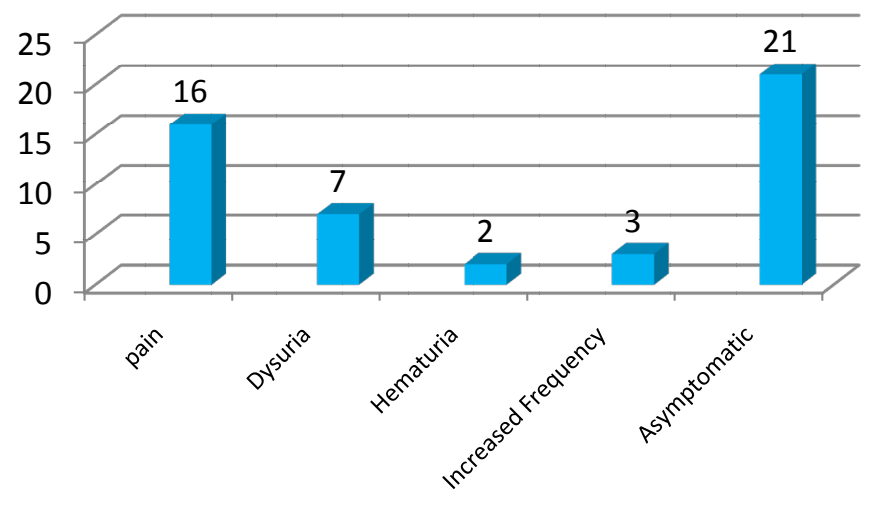

Figure 1. Graphical representation of symptoms of patients.

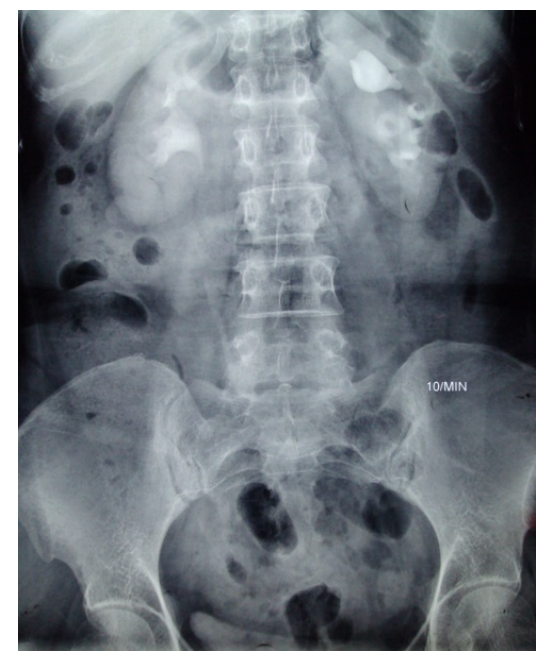

Image 1. IVU image showing delayed contrast excretion on left side due to hydronephrosis.

Magnetic Resonance Urography (MRU) was done in all patients after informed consent of Patient (Images 2-4). Out of 49 involved renal units Parenchymal thickness was decreased in 10 renal units and contrast execration was decreased in 8 units. Hydronephrosis was found in 49 (100\%) of renal units with 9 (18.3\%) showed mild hydronephrosis 13 (26.5\%) showing moderate hydronephrosis and 27 (55.1\%) severe hydronephrosis. Pelvi-calycel system was grossly dilated in 17 (34.69\%). Narrow segment PUJ obstruction was found in 41 (83.6\%) renal units while in 3 patient PUJO was not found (Table 3). Aberrant vessel was detected in 1 patient with Gd-MRU. PUJ obstruction was confirmed in 45 patients on surgery for which Anderson-Hynes pyeloplasty was done in all 
Table 2. Sensitivity and specificity of different modalities against MRU. For diagnosing primary PUJ Obstruction the sensitivity and specificity of different modalities as against MRU are as, USG 73.3\% and 50\%, IVP 85.3\% and 66.7\%. respectively.

\begin{tabular}{|c|c|c|c|c|c|}
\hline \multicolumn{6}{|c|}{ MRU } \\
\hline & & \multicolumn{2}{|c|}{ Present } & \multicolumn{2}{|c|}{ Absent } \\
\hline & & $\mathrm{n}$ & $\%$ & $\mathrm{~N}$ & $\%$ \\
\hline \multirow{2}{*}{ USG } & Present & 30 & 73.2 & 2 & 50.0 \\
\hline & Absent & 11 & 26.8 & 2 & 50.0 \\
\hline \multirow{2}{*}{ IVP } & Present & 35 & 85.3 & 4 & 66.7 \\
\hline & Absent & 6 & 14.6 & 3 & 33.3 \\
\hline
\end{tabular}

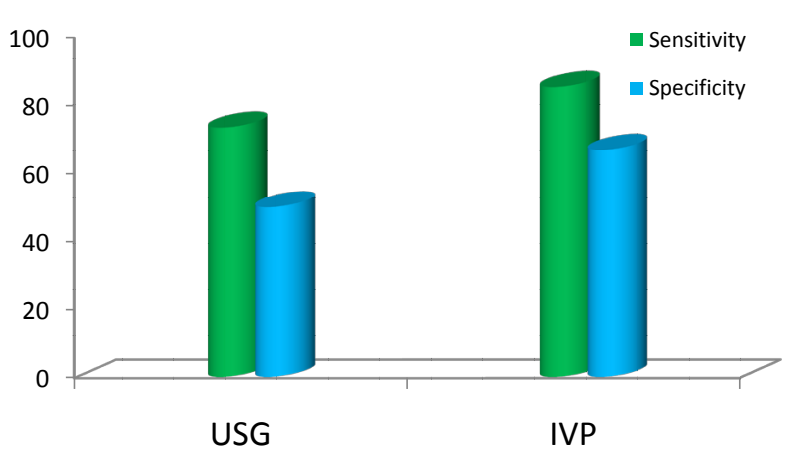

Figure 2. Sensitivity and specificity of different modalities against MRU.

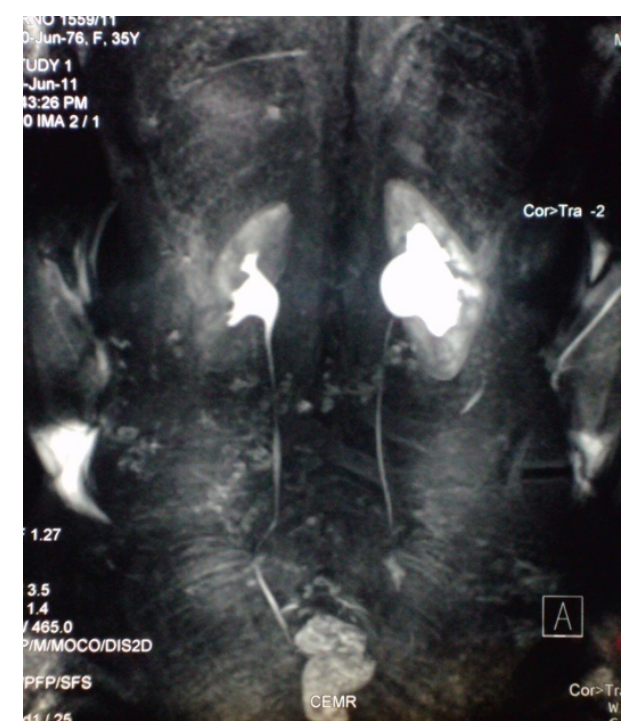

Image 2. CEMR showing dilated left renal pelvis secondary to PUJO.

patients. Intra-operatively 2 patients were found to have aberrant lower pole vessel as cause of obstruction.

Taking surgery as gold standard for confirming the presence of PUJ Obstruction, the sensitivity of different imaging modalities was 73.3\% for USG, 86.5\% for IVP and 91.2\% for MRU. 31 (69\%) of patients had PUJO on left side while 14 (31\%) had on right (Table 4).

The mean hospital stay was 7 days (ranging from 4 - 11 days), all patients were catheterized before surgery and catheter was removed on 3 - 6 days (mean = 3.2 day), the mean time for drain removal was 5.7 days. 4 of the patients developed SSI while 3 developed anstamotic leak which was managed non-operatively. All patients 


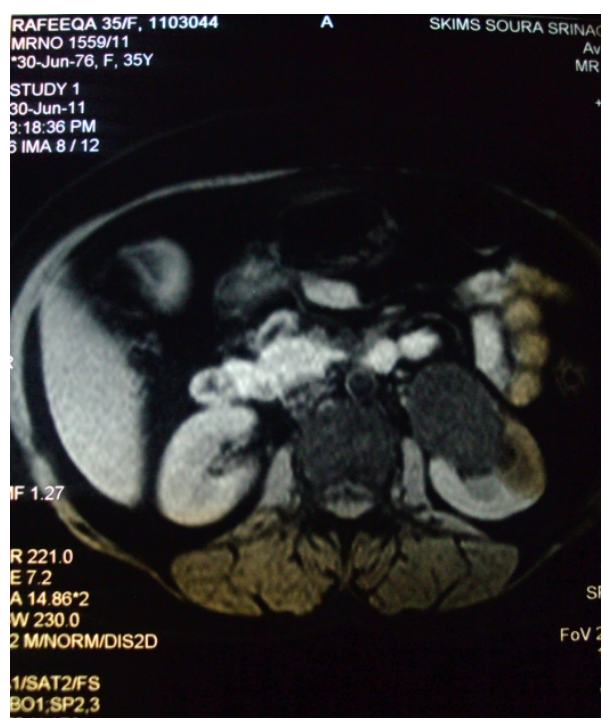

Image 3. T1weighted MRU image showing dilated left renal pelvis due to PUJO.

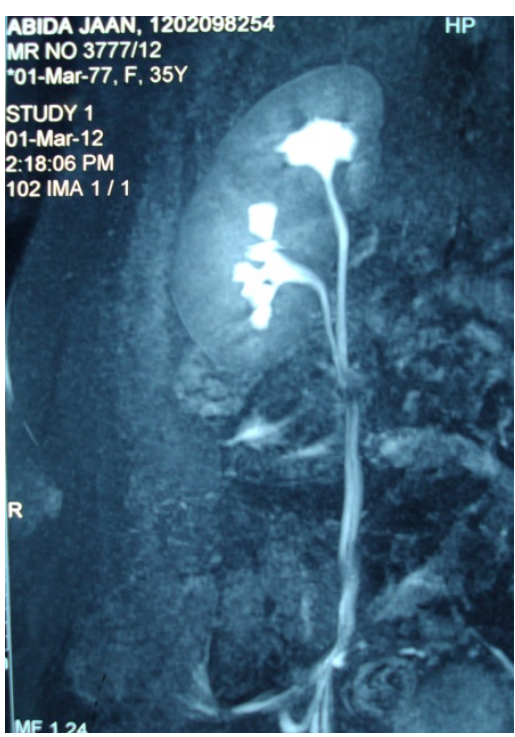

Image 4. CEMR showing duplex right PCS and proximal ureter.

were followed in our department with mean follow-up period of 3 months.

\section{Discussion}

IVU is useful for morphological diagnosis [17]. Contrast-enhanced MRU produces high-resolution images resulting from the accumulation of bright contrast material in the collecting system and the ureter [18]. Static MRU is very accurate in diagnosing the level and cause of obstruction, especially if the obstruction is not caused by calculi [17] but can not provide information about renal function. Therefore, Gd-MRI was developed to provide functional data where contrast-enhanced serial images are used to calculate renal clearance (MR clearance). A time-intensity curve is plotted [19] [20]. These findings suggest high accuracy of estimating renal clearance and diagnosis of obstruction by MRI. Gd-DTPA is an excellent indicator of renal function, as it is freely filtered through the glomeruli and it is neither absorbed nor secreted by renal tubules [20].

We carried a study entitled "Comparison of Magnetic Resonance Imaging (MRI) with Intravenous Pyelography 
Table 3. Renal Parameters on MRU. All patients were subjected to Magnetic Resonance Urography (MRU) after informed consent from Patient. All renal units examined were normal in position. Contrast uptake on MRU was normal in 42 (85.7\%) renal units and decreased in $7(14.2 \%)$ units. Out of 49 involved renal units parenchymal thickness was decreased in 10 (20.4\%) renal units and contrast execration was decreased in 8 units. Hydronephrosis was found in 49 (100\%) of renal units with 9 (18.3\%) showed mild hydronephrosis 13 (26.5\%) showing moderate hydronephrosis and 27 (55.1\%) severe hydronephrosis. Narrow segment PUJ obstruction was found in 41 (83.6\%) renal units. Aberrant vessel was detected in 1 patient with Gd-MRU.

\begin{tabular}{|c|c|c|c|}
\hline \multicolumn{4}{|c|}{ MRU Scan } \\
\hline & & $\mathrm{n}$ & $\%$ \\
\hline Position & Normal & 49 & 100.0 \\
\hline \multirow{2}{*}{ Up Take } & Normal & 42 & 85.7 \\
\hline & Decreased & 7 & 14.2 \\
\hline \multirow{2}{*}{ Parenchymal Thickness } & Normal & 39 & 79.5 \\
\hline & Decreased & 10 & 20.4 \\
\hline \multirow{2}{*}{ Contrast Excretion } & Normal & 41 & 83.6 \\
\hline & Decreased & 8 & 16.3 \\
\hline \multirow{3}{*}{ Hydronephrosis } & Mild & 9 & 18.3 \\
\hline & Moderate & 13 & 26.5 \\
\hline & Severe & 27 & 55.1 \\
\hline Aberrant Vessel & yes & 1 & 2.0 \\
\hline
\end{tabular}

Table 4. Sensitivity of different modalities against surgery. Taking surgery as gold standard for confirming the presence of PUJ Obstruction, the sensitivity of different imaging modalities was 73.3\% for USG, 86.6\% for IVP, 91.1\% for MRU.

\begin{tabular}{|c|c|c|c|c|c|c|c|}
\hline & \multirow[b]{2}{*}{ PUJO } & \multicolumn{2}{|c|}{ MRU } & \multicolumn{2}{|c|}{ IVP } & \multicolumn{2}{|c|}{ USG } \\
\hline & & Present & Absent & Present & Absent & Present & Absent \\
\hline surgery & present & 41 & 4 & 39 & 6 & 33 & 12 \\
\hline \multicolumn{2}{|c|}{ sensitivity } & \multicolumn{2}{|c|}{$91.1 \%$} & \multicolumn{2}{|c|}{$86.6 \%$} & \multicolumn{2}{|c|}{$73.3 \%$} \\
\hline
\end{tabular}

in evaluation of patients with Hydronephrosis on Ultrasonography” in the departments of Urology and Radiodiagnosis of our institute. Our study included 49 patients who visited our OPD and were found to have hydronephrosis on USG. Patients with missed data and those lost to followup were excluded from the study. All patients were subjected to IVP and Gd-MRU. In our study the sensitivity of IVP was $86.5 \%$ while that of MRU was $91.2 \%$ respectively which is at par with other studies (Katzberg RW, Buonocore MH, Ivanovic M et al).

MRI machines are not available everywhere because they are expensive. The long post-image processing time, and the need for an experienced radiologist to interpret the image. The expense of preoperative comprehensive MRI might be compensated as it can replace several imaging method. The long post-processing time can be reduced by improving the software and the experience in interpretation of the different MRI techniques.

Our study was performed on $1.5 \mathrm{~T}$ magnetic resonance imaging unit (Magnetom Avento; Siemens, Erlangen Germany).

Gadolinium is exclusively excreted through kidneys therefore has prolonged half life in patients with renal failure. The possible causal link between NFS and Gd containing contrast materials used in MRI was first identified by Grobner and has been reported in patients with chronic severe renal failure with GFR $<30 \mathrm{ml} / \mathrm{min} / 1.73$ $\mathrm{m}^{2}$, patients with acute renal insufficiency and in patients with Hepato-renal syndrome [21] [22]. In 2007 the pharmacovigilance working party of European Medicines Agency (EMEA) announced that Gadolinium is contraindicated in patients with GFR $<30 \mathrm{ml} / \mathrm{min}$.

Although commenting on this will be too early at this point due to short follow-up period, none of patients in our study developed NSF.

\section{Conclusion}

We conclude that Gd-MRU provides superior anatomical and functional information about renoureteral units as 
compared to IVP. MRU is investigation of choice in patients at risk of radiation exposure and allergy to iodinated contrast material. It provides a complete diagnostic evaluation of entire urinary tract in a single session. Gd-MRU can be considered a better alternative to like IVU for estimating differential renal function and diagnosing obstruction. We conclude that comprehensive MRI is a good and valuable alternative to IVP in preoperative evaluation of patients with PUJO.

\section{References}

[1] Klahr, S. (1999) The Geriatric Patient with Obstructive Uropathy. Geriatric Nephrology and Urology, 9, 101-107. http://dx.doi.org/10.1023/A:1008387116491

[2] Gulmi, F.A., Felson, D. and Vaughan, E.D. (1998) The Pathophysiology of Urinary Tract Diseases. Campbells Urology, 342-385.

[3] Murnaghan, G.F. (1958) The Dynamics of the Renal Pelvis and Ureter with Reference to Congenital Hydronephrosis. British Journal of Urology, 30, 321-324. http://dx.doi.org/10.1111/j.1464-410X.1958.tb03525.X

[4] Hanna, J.K. (2000) Antenatal Hydronephrosis and Ureteropelvic Junction Obstruction: The Case for Early Intervention. Urology, 55, 612-615. http://dx.doi.org/10.1016/S0090-4295(00)00460-X

[5] Jara, H., Barish, E.K., Yucel, E.R., Melhem, S., Hussain, J. and Ferrucci, T. (1998) MR Hydrography. Theory and Practice of Static Fluid Imaging. American Journal of Roentgenology, 170, 873-882. http://dx.doi.org/10.2214/ajr.170.4.9530026

[6] Lauterber, P.C. (1973) Image Formation by Induced Local Interaction: Examples of Employing Nuclear Magnetic Resinanace. Nature, 242, 190-191. http://dx.doi.org/10.1038/242190a0

[7] O’Malley, M.E., Soto, J.A., Yucel, E.K. and Hussain, S. (1997) MR Urography: Evaluation of a Three-Dimensional Fast Spin-Echo Technique in Patients with Hydronephrosis. American Journal of Roentgenology, 168, 387-392. http://dx.doi.org/10.2214/ajr.168.2.9016213

[8] Bassignani, M.J. (2006) Understanding and Interpreting MRI of the Genito-Urinary Tract. Urologic Clinics of North America, 33, 135-151.

[9] Valtuille, G.R., Ai-Valtuille, G., Abascal, F., Cerezal, L. and Arguello, M.C. (2006) Magnetic Resonance Urography: A Pictorial Overview. British Journal of Radiology, 79, 614-626. http://dx.doi.org/10.1259/bjr/21075982

[10] Murphy, K.J., Brunberg, J.A. and Cohan, R.H. (1996) Adverse Reactions to Gadolinium Contrast Media: A Review of 36 Cases. American Journal of Roentgenology, 167, 847-849. http://dx.doi.org/10.2214/ajr.167.4.8819369

[11] Runge, V.M. (2001) Safety of Magnetic Resonance Contrast Media. Topics in Magnetic Resonance Imaging, 12, 309314. http://dx.doi.org/10.1097/00002142-200108000-00007

[12] Marckmann, P., Skov, L., Rossen, K., Dupont, A., Damholt, M.B., Heaf, J.G., et al. (2006) Nephrogenic Systemic Fibrosis: Suspected Etioliogy Role of Gadodiamide Used for Contrast Enhanced MRIJ. American Society of Nephrology, 17, 2359-2362.

[13] Grobner, T. (2006) Gadolinium-A Specific Trigger for the Development of Nephrogenic Systemic Fibrosis. Nephrology Dialysis Transplantation, 21, 1104-1108. http://dx.doi.org/10.1093/ndt/gfk062

[14] Katzberg, R.W., Buonocore, M.H., Ivanovic, M., et al. (2001) Functional, Dynamic, and Anatomic MR Urography: Feasibility and Preliminary Findings. Academic Radiology, 8, 1083-1099. http://dx.doi.org/10.1016/S1076-6332(03)80720-1

[15] Martin, X. and Rouvière, O. (2001) Radiologic Evaluations Affecting Surgical Technique in Ureteropelvic Junction Obstruction. Current Opinion in Urology, 11, 193-196. http://dx.doi.org/10.1097/00042307-200103000-00011

[16] Zamparelli, M., Cobellis, G., Rossi, L., Valeri, G., Amici, G. and Martino, A. (2003) Detection of Crossing Vessels at the Ureteropelvic Junction with Fast MRI. Pediatria Medica e Chirurgica, 25, 50-52.

[17] Shokeir, A.A., El-Diasty, T.A., Eassa, W., Mosbah, A., El-Ghar, M.A., Mansour, O., et al. (2004) Diagnosis of Ureteral Obstruction in Patients with Compromised Renal Function: The Role of Noninvasive Imaging Modalities. Journal of Urology, 171, 2303-2306. http://dx.doi.org/10.1097/01.ju.0000124928.69055.10

[18] Public Health Advisory: Gadolinium Containing Contrast Agents for Magnetic Resonance Imaging: Omniscan, OptiMARK, Magnevest, Prohance and Multihance. US Food and Drug Administration, Centre for Drug Evaluation and Research. www.fda.gov/cder/advisory/gadolinium.agents.htm

[19] El-Diasty, T., Mansour, O. and Farouk, A. (2003) Diuretic Contrast-Enhanced Magnetic Resonance Urography versus Intravenous Urography for Depiction of Nondilated Urinary Tracts. Abdominal Imaging, 28, 135-145. http://dx.doi.org/10.1007/s00261-002-0010-X

[20] Wolf, G.L., Hoop, B., Cannillo, J.A., Rogowska, J.A. and Halpern, E.F. (1994) Measurement of Renal Transit of Ga- 
dopentate Dimeglumine with Echo-Planar MR Imaging. Journal of Magnetic Resonance Imaging, 4, 365-372. http://dx.doi.org/10.1002/jmri.1880040323

[21] Nortier, J. and del Marmol, V. (2007) Nephrogenis Systemic Fibrosis-The Need for a Multidisciplinary Approach. Nephrology Dialysis Transplantation, 22, 3097-3101. http://dx.doi.org/10.1093/ndt/gfm430

[22] Baron, P.W., Cantos, K., Hillebrand, D.J., Hu, K.Q., Ojogho, O.N., Nehlsen-Cannarella, S., et al. (2003) Nephrogenic Fibrosing Dermopathy after Livertransplantion Successfully Treated with Plasmopheresis. American Journal of Dermatopathology, 25, 204-209. http://dx.doi.org/10.1097/00000372-200306000-00004 